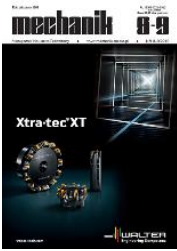

\author{
How to cite this article: \\ Author: Jarosław Jankowski \\ Title of article: "Research and training car driving simulator with weight up to 3.5 tons dedicated to physical disabled \\ drivers" \\ Mechanik, No. 8-9 (2019) \\ DOI: https://doi.org/10.17814/mechanik.2019.8-9.69
}

\title{
Research and training car driving simulator with weight up to 3.5 tons dedicated to physical disabled drivers
}

\section{JAROSŁAW JANKOWSKI *}

Dr inż. Jarosław Jankowski, jajan@ciop.pl, https://orcid.org/0000-0002-4910-7904 - Centralny Instytut Ochrony Pracy - Państwowy Instytut Badawczy, Warszawa, Polska

The article presents the continuation of work related to the creation of a car driving simulator with a weight of up to 3.5 tons adapted to selected disabilities. The article contains a description of the developed motion platform with six degrees of freedom and the cockpit. In order to ensure the possibility of being managed by the largest group of people with physical disabilities, selected support solutions were implemented. These devices can be easily dismantled to test others. The platform together with the cockpit is controlled from the simulator application and the image is presented to the simulation participant in 3D projection glasses and optionally on a three-segment screen.

KEYWORDS: driving simulator, people with physical disabilities, virtual reality

\section{Introduction}

This paper presents the continuation of activities carried out while creating the test stand in the form of a car simulator with a weight of up to $3.5 \mathrm{t}$, designed to test the suitability of various solutions for driving a motor vehicle by a person with physical disabilities.

The task was divided into three stages. The results of the first stage were included in the author's work [1]. At this stage, the planned research methodology and research tools used were determined. The assumptions regarding the construction and use of the driving simulator as well as construction of its most important elements were presented.

Results of the second stage of the project are presented below.

\section{Test stand - components of the driving simulator}

The following main components can be distinguished in the simulator under development:

- mobile platform with six degrees of freedom,

- simulator cockpit with adaptive instrumentation,

- simulator application,

- image projection method.

\section{Mobile driving simulator platform}

The mobile platform (fig. 1) was designed in accordance with previously adopted assumptions. It was made in the architecture of the Gough-Stewart hybrid platform [2]. Three drive sections are arranged on three sides of an equilateral triangle (with a radius of inscribed circle equal to $550 \mathrm{~mm}$ ). The platform leg consists of a $230 \mathrm{~mm}$ long crank and a $600 \mathrm{~mm}$ long pusher with rod heads at the ends. The platform is equipped with limit switches and the necessary wiring of the inverters in the control cabinet is made. 


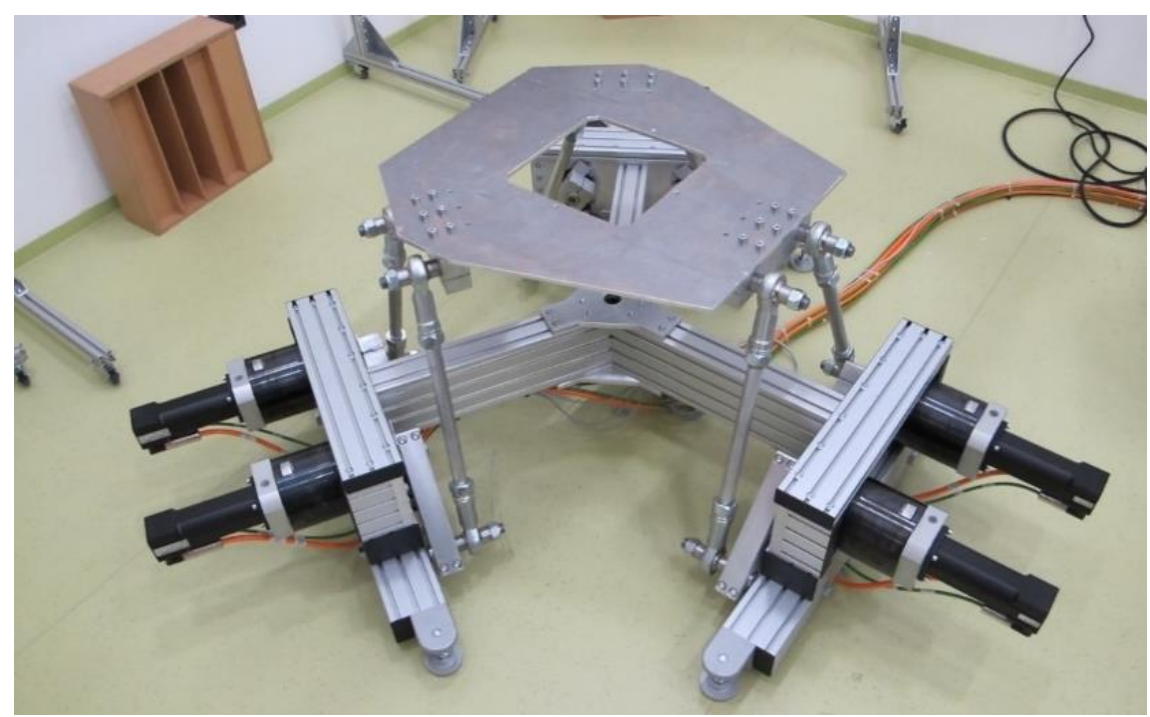

Fig. 1. Final stage of assembly of the mobile platform with six degrees of freedom

In order to ensure control of the parallel manipulator, a controller was made (fig. 2) based on the ARM Cortex-M4F microcontroller together with the CAN interface handling system.

The mobile platform motion control application (fig. 2) was created in Unity 3D software. Using the solid models of the mobile platform and the Nvidia PhysX physics engine, a multi-element system with a reconstituted kinematic structure was built in the Unity 3D environment.

The developed platform motion control script allows for performing the platform effector movements, i.e. rotation around adopted $X, Y$ and $Z$ axes, and displacement along the $X, Y, Z$ axes by moving the slider marker (graphic elements of the user interface) located on the left side of the window.

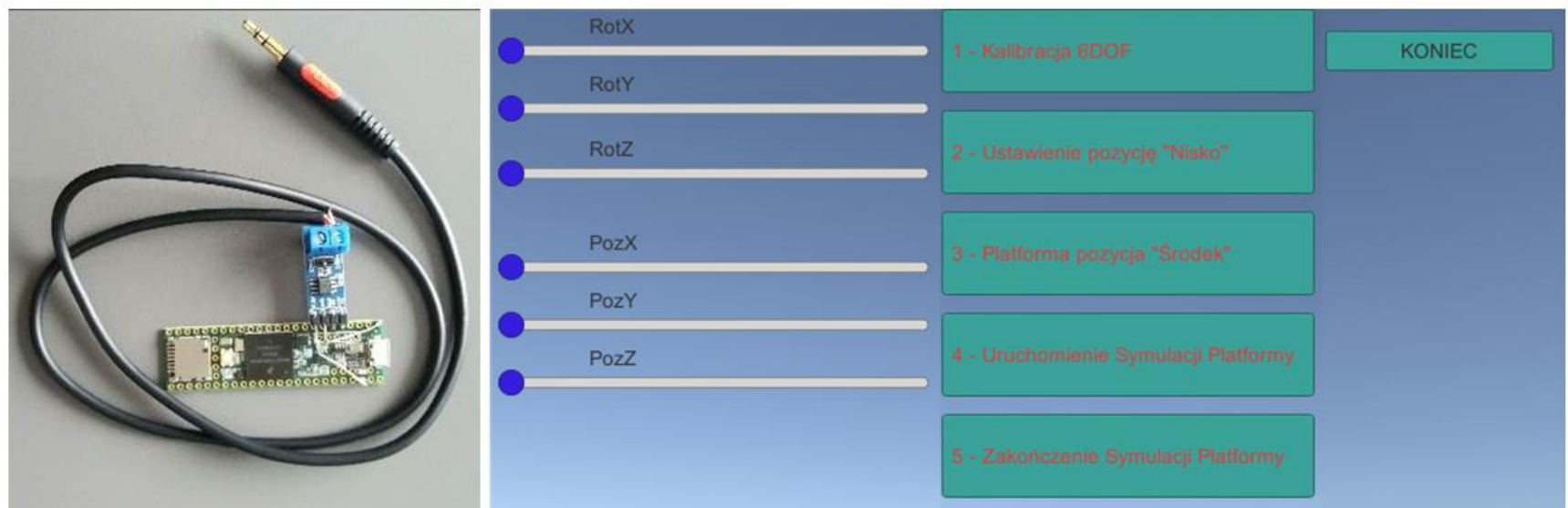

Fig. 2. Mobile platform drive unit driver (left) and mobile platform motion control interface (right)

This script can then be imported into the target application, i.e. into the car driving simulator.

The platform has mechanical crank movement restrictions, its control system uses a safety switch, and it will also be fenced off to prevent access by third parties.

\section{Simulator cockpit with adaptive instrumentation}

From the user's point of view, the main element is the car cockpit (fig. 3). It consists of an aluminum structure with mounted:

- actual driver's seat (it is possible to change the position of the seat relative to the dashboard),

- actual steering column with steering wheel (it is possible to change the angle of the steering wheel),

- brake and accelerator pedal (product Thrustmaster T3PA Pro),

- real automatic gearbox,

- hand brake,

- stop simulation button,

- seat belts. 
The cockpit is equipped with a driver that supports the car indicator panel, which additionally downloads information about the state of the turn signal levers, car wipers, high beam, switch of dipped headlights and car ignition as well as angular position of the steering wheel.

The simulator application sends information about the current speed and engine rotation number to set the indicators of the real panel, and receives information about the status of individual controls.

An important element is also the steering force feedback system, which is based on a servo motor with a planetary gear (fig. 3).

Simulator cockpit has been equipped with elements adapting the car to the needs of people with physical disabilities.

The offers of companies creating and distributing adaptive instrumentation of cars were reviewed, consultations with employees of these companies were carried out and the "List of adaptation of the car depending on the type of dysfunction" [3], prepared by the Center for Automotive Services for People with Disabilities, was reviewed. On this basis, the following seven products were selected:

- $\quad$ RGH V from CEBRON Sp. z o.o. [4] (fig. 4a) - device for manual gas and brake control;

- gas and brake pedal cover, designed for people, who do not control the movement of lower limbs;

- knob handlebar grip (fig. 4b);

- two-pin steering wheel holder (fig. 4c), guaranteeing stable support and strong hand grip, designed for people with hand inertia [5];

- turn signal lever (controlled by right hand);

- bench that makes getting into a person with lower limb dysfunction easier;

- accelerator and brake pedal extensions. An automatic gearbox is also a convenience for persons driving the vehicle with lower and/or upper limbs dysfunctions.

Using the software solutions in the cockpit, one can change the position of the accelerator and brake pedals.

All the above mentioned equipment can be easily dismantled so that new adaptive equipment can be prototyped.

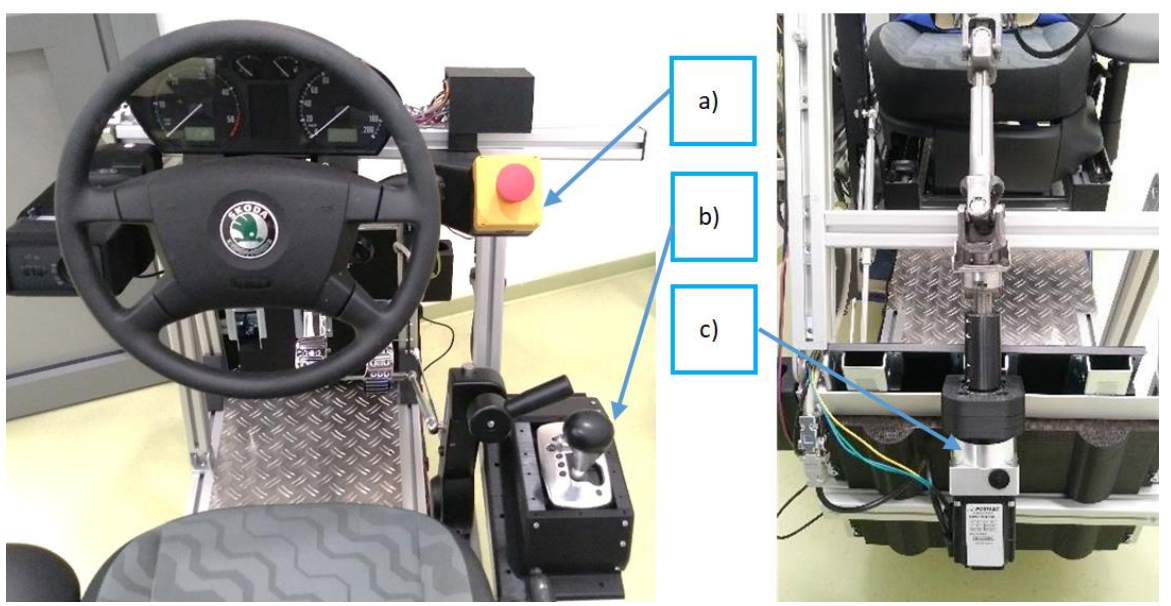

Fig. 3. Simulator cockpit (user perspective view): a) simulation stop button, b) automatic gearshift lever, c) steering force feedback servo motor (cockpit front view)

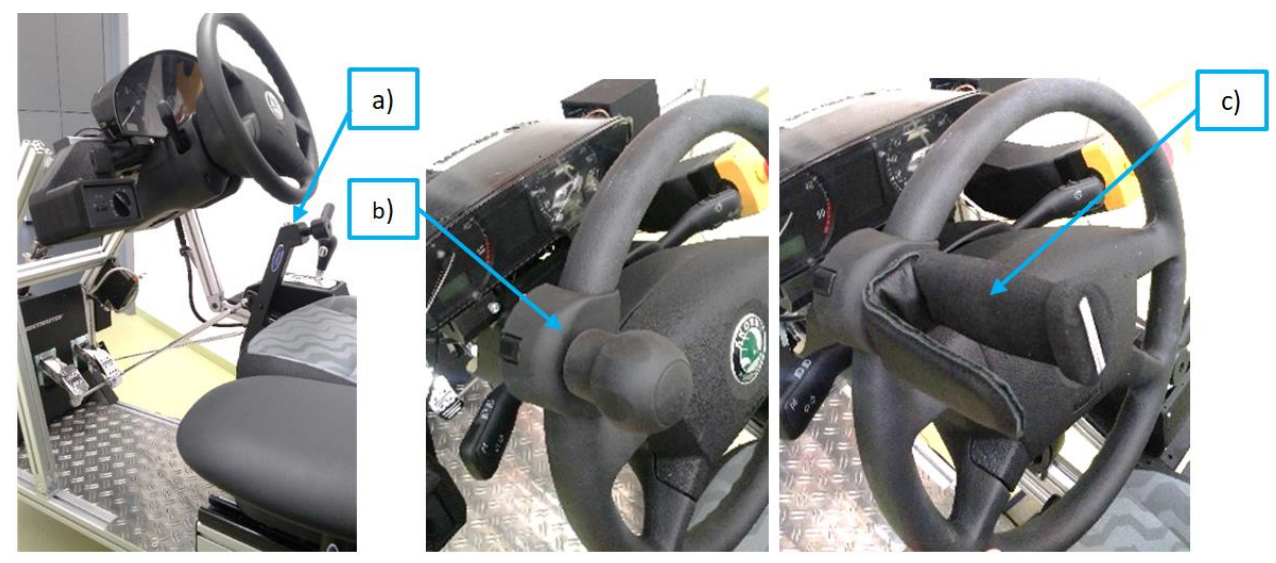

Fig. 4. Adaptive instrumentation: a) RGH V from CEBRON Sp. $z$ o.o. - device for manual control of gas and brake, b) handlebar handle - handlebar knob, c) two-pin handle 


\section{Simulator application}

In the Unity 2018 software [6], a simulator application has been developed that consists of a virtual environment, a simulated virtual car and scripts of object interaction in the virtual environment.

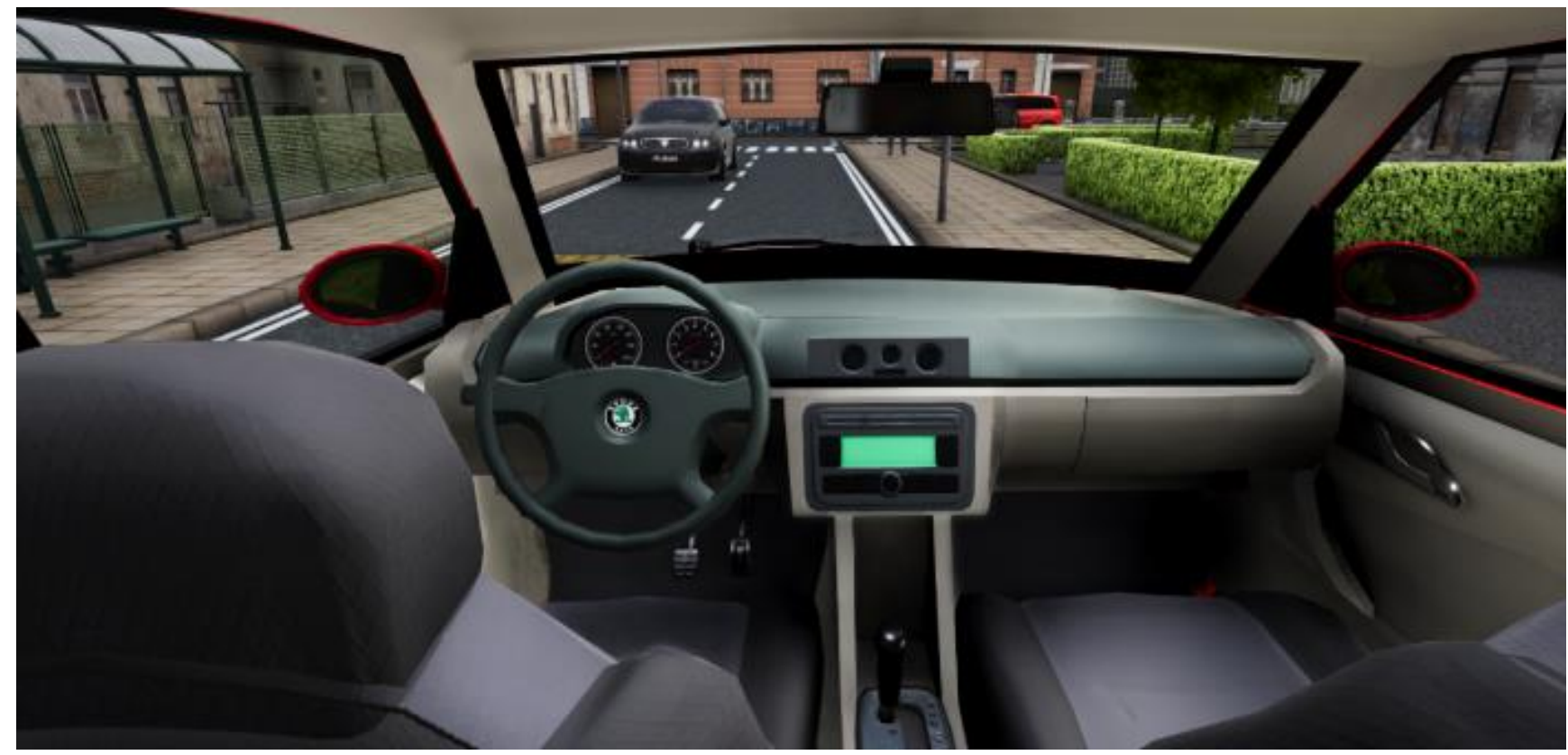

Fig. 5. Virtual environment of the driving simulator - view from inside the car

Virtual environment is equipped with: buildings, roadways, auxiliary elements of "backgrounds", elements of road infrastructure, road signs, computer controlled vehicles, avatars of moving people. It covers several urban areas, separated by a mountain massif, and forest roads with short sections of residential areas.

The car selected is a minivan in the class up to 3.5 tons dmc, with an automatic transmission.

The car driving model is included in the professional "MS Vehicle System" package [7]. It allows to configure many parameters to adapt the driving model to a specific car.

The program enables wheel/road contact detection based on terrain texture or object markers with configurable friction value. It calculates the power and torque of an engine with adjustable power curve and RPM range. It supports the automatic transmission, uses differential effect and has the ability to set the center of gravity of the car. Additional elements such as sound and light control are an integral part of the package.

Parameters of the selected car driving model will be adjusted based on the experience of the co-contractors of the task and specifications of a given car model.

In urban areas, there is a programmed traffic light. On designated roads, there are other traffic participants moving in a certain area around the simulated car, and the avatars of passers-by are moving along the city sidewalks.

In the current version of the application, a route has been selected that the simulation participant should follow. It is directed by graphic signals displayed on the screen in the form of arrows and signs: STOP, START, UNDO, START. Providing information to participants with hearing loss will be done using graphical signals.

\section{Image projection methods}

According to the assumptions, projection of the simulated image will be implemented using 3D projection glasses and - optionally - screen projection. For screens projection, three screens are used, which are approximately $2 \mathrm{~m}$ away from the simulator user, with the side screens positioned at an angle of $120^{\circ}$ to the central screen. Below them, there is a curtain which ends at the height of the minimum position of the effector plane. The curtain is intended to reduce the level of anxiety resulting from the user being at a significant height during the simulation and thus - to reduce the incidence of simulation disease symptoms.

Three identical projectors working in 3LED technology were used for screen projection, with native resolution of $1980 \times 1200$ pixels $(60 \mathrm{~Hz})$ and 5000 ANSI brightness. In this projection method, the image of the side mirrors and rear view mirror is generated by the simulator application and displayed in the appropriate place on the side screens. 
The eyepiece projection was implemented using HTC Vive Pro glasses with integrated stereo headphones. Important elements of the screen projection set are the motion tracking system and the device enabling wireless transmission of video and audio.

\section{Summary}

The described and made elements of the simulator create a stand - both training and research - designed to test new concepts of solutions aimed at adapting the car cockpit to individual needs, including people with disabilities. It is also planned to use virtual reality techniques to virtual prototype devices supporting drivers with hearing loss, e.g. devices presenting additional information about traffic in the form of properly crafted visual data, e.g. in the form of HUD (head up display). Virtual prototyping will concern, among others, forms of the human-computer interface.

Simulator subsystems discussed have been started and functionally checked. Full tests of the simulator and its components will be performed at the last stage and confirmed in the planned tests. These tests will allow for objective and subjective evaluation of the car driving simulator by the target group. According to the developed research concept, 20 people will participate (including 10 people with lower and upper limb dysfunction).

The paper was prepared on the basis of results of the fourth stage of the multiannual program "Improvement of safety and working conditions", financed in 2017-2019 in the scope of tasks of state services by the Ministry of Family, Labor and Social Policy.

Program coordinator: Central Institute for Labor Protection - National Research Institute.

\section{REFERENCES}

[1] Jankowski J., Grabowski A. „Koncepcja badawczo-szkoleniowego symulatora samochodu osobowego do badania urządzeń wspomagających kierowców z niepełnosprawnością ruchową". Mechanik. 7 (2018): 573-575.

[2] Stewart D. "A platform with six degrees of freedom". Proceedings of the Institution of Mechanical Engineers. 180, 1 (1965): 371-386.

[3] https://cum.its.waw.pl/doc_media/wezel_3884/Adaptacje_a_rodzaj_dysfunkcji.pdf (29.03.2019).

[4] http://www.autosprawni.pl/k1/index.html (29.03.2019).

[5] https://www.braunability.eu/en/products/driving-aids/steering-devices (29.03.2019).

[6] https://unity.com (29.03.2019).

[7] https://assetstore.unity.com/packages/tools/physics/ms-vehicle-system-free-version-90214 (29.03.2019). 